\section{Primary Natural Killer-Cell Lymphoma of the Gastrointestinal Tract}

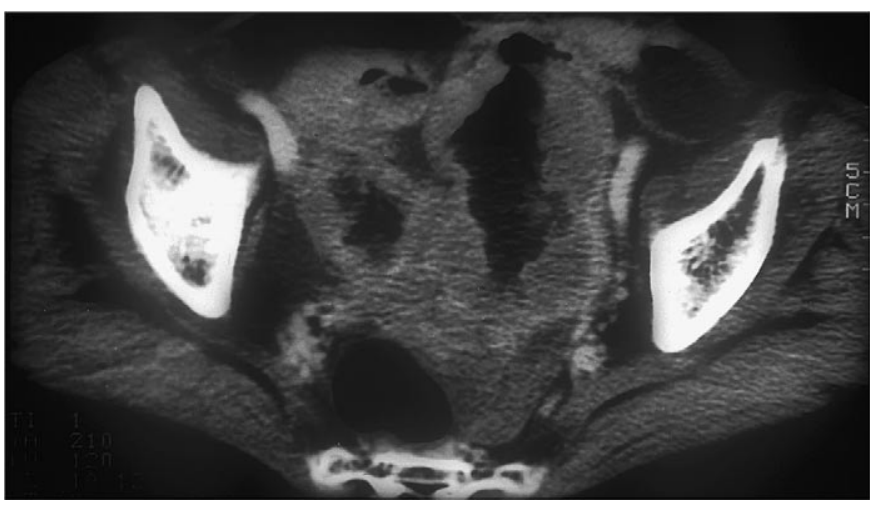

Figure 1 A 70-yearold woman was admitted with lower abdominal pain. An 8-cm mass was palpable in the left lower quadrant of the abdomen. Abdominopelvic computed tomography showed irregular thickening of the small bowel on the left side of the abdominal cavity.
H. W. Chung, S. J. Lee, S. W. Park, S. Y. Song, J. B. Chung, J. K. Kang Department of Internal Medicine, Institute of Gastroenterology, Yonsei University College of Medicine, Seoul, South Korea

Corresponding Author

\section{S. J. Lee, M.D.}

Department of Internal Medicine Yong-dong Severance Hospital Yonsei University College of Medicine Gangnam-gu

Dogok-dong 146-92

Seoul 135-720

South Korea

Fax: $\quad+82-2-34633882$

E-mail: leesj@yumc.yonsei.ac.kr

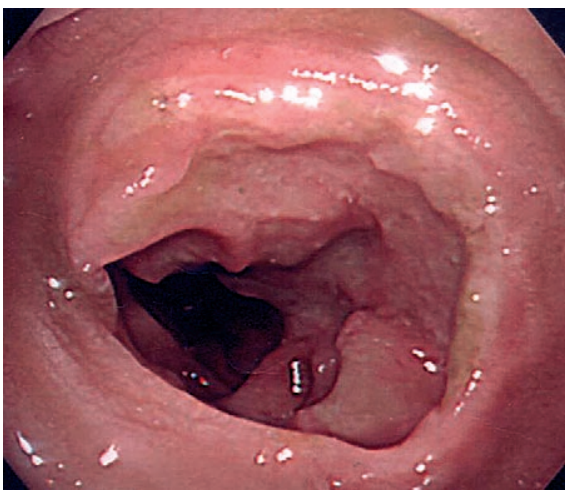

Figure 2 Esophagogastroduodenoscopy demonstrated an ulcerated, infiltrating lesion which occupied $50 \%$ of the lumen in the third part of the duodenum.

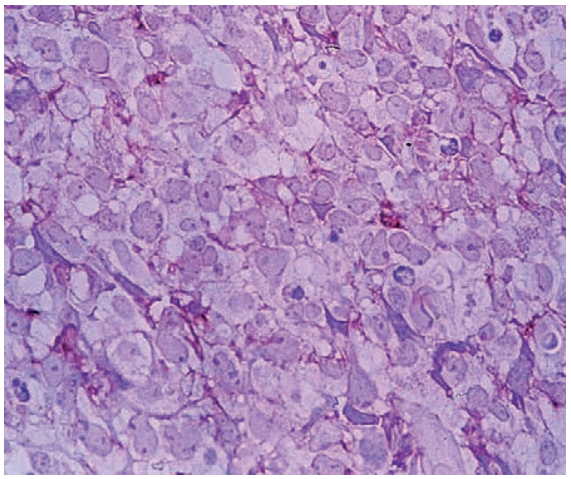

Figure 3 Histological examination of the duodenal biopsy revealed a true natural killer-cell lymphoma, with transmural infiltration of large pleomorphic cells. These cells were CD56-positive (Anti-CD56; Santa Cruz Biotechnology Inc., Santa Cruz, California, USA; × 400), but did not express surface CD3 or T-cell lineage.

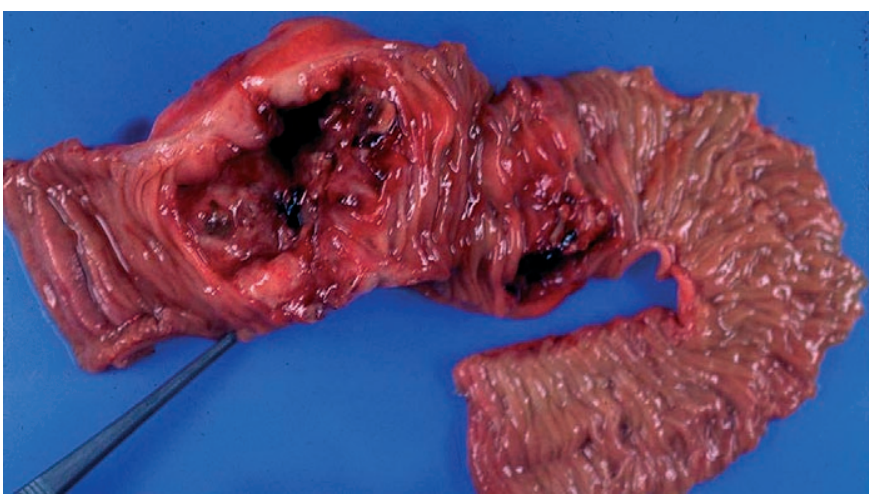

Figure 4 An ulcerated and excavated mass in a portion of resected jejunum showing multifocal hemorrhage and necrosis. Histologically, this was also revealed to be a true natural killer-cell lymphoma. 